\title{
Do livro ao cinema: Iracema e Avatar
}

Maria Aparecida Barbosa Vianna e Katy Evelin Almeida Santos ${ }^{1}$

\section{Resumo}

Nossa pesquisa recai sobre a criação das personagens e das cenas do romance Iracema, de Alencar e da produção cinematográfica Avatar, de Cameron. Nos elementos apresentados presenciamos a intertextualidade, a representação, a criação das personagens e outros pontos em comum. Apesar da distância cronológica, ambas se aproximam na intertextualidade implícita (Kristeva), na representação das cores, símbolos, enredo, cenas e ações. Obtemos um diálogo (Bakhtin), através dos pontos de convergência entre as obras. $\mathrm{O}$ apoio dos autores, aqui citados, fundamentam nossa pesquisa nas fronteiras das produções artísticas, na literatura, na construção visual e nos discursos múltiplos das linguagens apresentadas

Palavras-chave: arte; literatura; cinema

\begin{abstract}
Our research rests on the creation of characters and scenes from the novel - Iracema, by Alencar and filmmaking Avatar, by Cameron. In documents submitted witnessed intertextuality, representation, creation of characters and other points in common. Despite the chronological distance, both approximate the implicit intertextuality (Kristeva), in representation of colors, symbols, plot, scenes and actions. We obtain a (Bakhtin) dialogue, through the points of convergence between the works. The support of the authors cited here, base our research on the frontiers of artistic productions, literature, visual construction and multiple discourses of languages presented.
\end{abstract}

Key-words: art; literature; cinema

Introdução

Após um longo processo de alterações das mídias, iniciando com as leituras e posteriormente com o rádio, a fotografia, o cinema, a televisão e atualmente as novas tecnologias digitais, sabemos que cada vez mais a cultura contemporânea adquire aspectos visuais, muitas vezes esses se sobressaem em obras literárias ou audiovisuais, cotidianamente ganham mais espaço na preferência do leitor

\footnotetext{
${ }^{1}$ Unesp; Faculdade de Arquitetura, Artes e Com., Bauru ; e-mail: mrciavianna@yahoo.com.br; Imes (Instituto Municipal de Ensino Superior de São Manuel), São Manuel; São Paulo; e-mail: katyevelin89@yahoo.com.br.

Revista Leitura V.2 no 54 - Júlio/Dez 2014 - Número temático: Leituras interartes. Do liuro ao cinema: Iracema e Avatar - Maria Aparecida Barbosa Vianna e Katy Evelin Almeida Santos. p. 68- 80
} 
contemporâneo, de perfil dinâmico e expressivo. Nosso mundo encontra-se repleto de imagens, por isso aprender a "vê-lo" tornou-se fundamental.

O homem passa um bom tempo de sua vida em busca do saber, da aprendizagem, cria repertórios e aos poucos consegue identificar em seus objetos de estudos elementos que se entrecruzam entre uma leitura, ou um filme. A ideia deste artigo, cujo desenvolvimento elenca a intertextualidade entre o texto literário Iracema (Alencar, 1865, edição de 1998) e o texto fílmico Avatar, lançado em 2009, dirigido por James Cameron, veio no simples ato de sentar-se frente à tela do cinema para assistir a um lançamento cinematográfico. No desenrolar das cenas, nitidamente percebeu-se que a base do enredo encontrava-se em outra produção, no caso, a literária. Aos poucos, com orientação e pesquisa, chegamos aos pontos de convergência aqui apresentados.

A obra alencariana, um livro indianista, publicado no século XIX, traz o romance entre uma nativa, Iracema e o estrangeiro Martim, assim como a relação de ambos com a natureza. Paralelamente a essa ficção, encontramos, mais tarde, já no século XXI, um processo intertextual, devido à semelhança, o filme Avatar, cuja data fictícia remete-nos ao ano 2154 D.C. Tais aspectos instigam o aprofundamento no assunto, pois se percebe um diálogo entre os textos, facilitando o trabalho intertextual, no qual o foco centra-se nos elementos da natureza e no romantismo. Quanto ao espaço, o desenvolvimento de Iracema se passa nas matas brasileiras; no filme Avatar há um lugar imaginário, em meio à última floresta, denominado Planeta de Pandora.

Como referenciais teóricos ao estudo, pesquisa e escrita deste artigo, buscamos os textos de (Bakhtin,1992), Walty (2000), Lucas (2001), Pellegrini (2003), Koch (2008) e Koch e Elias (2010).

Ao nos concentrarmos nas leituras, entendemos que para Walty (2000, p. 7) a leitura torna-se "um processo associativo que promove a interação escrita/imagem em diversos sentidos". Ler um livro, para a autora, consiste em deixar fluir emoções e sensações variadas, provocadas pelas imagens criadas pelo ato de ler na mente do leitor, e posteriormente despertando sentimentos e emoções no espectador do filme.

Pellegrini (2003, p. 16) coloca-nos a possibilidade da percepção ao citar "uma conexão pode ser muitas vezes clara, outras vezes apenas sugerida entre os textos ficcionais e os elementos das linguagens visuais", levando à percepção da complexa 
relação entre a literatura e o cinema, principalmente quando há características de intertextualidade. A autora lembra que inúmeros filmes contêm "dialogicamente, alusões ou referências literárias, breves ou extensas, implícitas ou explícitas" (PELLEGRINI, 2003, p. 37).

Para expormos os pensamentos e ideias sobre o dialogismo, precisamos compartilhar dos pensamentos de (BAKHTIN,1992, p. 123),

\begin{abstract}
"O diálogo, no sentido estrito do termo, não constitui, é claro, senão uma das formas, é verdade que das mais importantes, da interação verbal. Mas pode-se compreender a palavra 'diálogo' num sentido mais amplo, isto é, não apenas como a comunicação em voz alta, de pessoas colocadas face a face, mas toda comunicação verbal, de qualquer tipo que seja. O livro, isto é, o ato de fala impresso, constitui igualmente um elemento da comunicação verbal. Ele é objeto de discussões ativas sob a forma de diálogo e, além disso, é feito para ser apreendido de maneira ativa, para ser estudado a fundo, comentado e criticado no quadro do discurso interior, sem contar as reações impressas, institucionalizadas, que se encontram nas diferentes esferas da comunicação verbal (críticas, resenhas, que exercem influência sobre trabalhos posteriores, etc.). Além disso, o ato de fala sob a forma de livro é sempre orientado em função das intervenções anteriores na mesma esfera de atividade, tanto as do próprio autor como as de outros autores: ele decorre portanto da situação particular de um problema científico ou de um estilo de produção literária. Assim, o discurso escrito é de certa maneira parte integrante de uma discussão ideológica em grande escala: ele responde a alguma coisa, refuta, confirma, antecipa as respostas e objeções potenciais, procura apoio, etc."
\end{abstract}

Sob essa óptica, percebe-se o diálogo na linguagem, pois se refere a qualquer forma de discurso, desde os artísticos até os literários, e esses se inter-relacionam em contextos históricos, com a possibilidade de serem compartilhados entre os interlocutores, mesmo em tempos e locais diversos, a partir de enunciados constituídos de criações anteriores ou passadas, quer o precedam ou sucedam na cadeia de comunicação.

Em sua teoria, Bakhtin explicita que a constituição de um discurso sempre considera o de outro, essa presença constitui seu texto, ou seja, provém de um discurso alheio, nada é particular, único, há sempre uma voz externa, então entendemos as relações de sentido estabelecidas entre os enunciados.

No diálogo entre as obras por nós citadas e pesquisadas, incorporam-se elementos narrativos, cenas, cores tipicamente tropicais, centralização temática e foco dos personagens na composição do filme. São pequenos aspectos externos e Revista Leitura V.2 no 54 - Júlio/Dez 2014 - Número temático: Leituras interartes. Do liuro ao cinema: Iracema e Avatar - Maria Aparecida Barbosa Vianna e Katy Evelin Almeida Santos. p. 68- 80 
visíveis marcadores do texto fílmico atribuídos a um discurso alheio, mas sem a separação nítida do enunciado citante e do citado.

Pretendemos, como objetivo deste texto, traçar caminhos ao leitor, auxiliando na identificação das semelhanças entre as obras, na percepção de quando se interligam, no entrecruzar dos textos, das falas, das ações e dos roteiros. Embora sejam de realidades distintas, tempos, personagens e locais, surgem em linguagens diferenciadas - a literária e a cinematográfica, porém, trazem em si momentos e cenas configurados através dos elementos implícitos em ambas as produções artísticas.

\section{Desenvolvimento: caminhos entrelaçados}

Muitos teóricos recentes discutem sobre obras refeitas a partir de outras. No caso desta pesquisa, pode-se falar em intertextualidade entre produções literárias e fílmicas, embora sejam de tempos tão distantes, no entanto remetem a aspectos parecidos, a intertextualidade se inseri de uma forma implícita

"a intertextualidade implícita ocorre sem citação expressa da fonte, cabendo ao interlocutor recuperá-la na memória para construir o sentido do texto, como nas alusões, na paródia, em certos tipos de paráfrases e ironias." (KOCH, 1991, 1997 a e b, 2004)

Há intertextualidade, afirma Bakhtin, quando "cada enunciado é um elo da cadeia muito complexa de outros enunciados" (apud KOCH, ELIAS, 2010, p. 78). Aqui, focamos a intertextualidade implícita, essa forma de representação ocorre quando surgem referências no texto sem mencionar a obra original (Koch, Bentes, Cavalcante, 2008). Para os autores, na intertextualidade implícita,

"O produtor do texto espera que o leitor/ouvinte seja capaz de reconhecer a presença do intertexto, pela ativação do texto fonte em sua memória discursiva, visto que, e tal não ocorrer, estará prejudicada a construção do sentido" (KOCH, BENTES, CAVALCANTE, 2008, p. 30).

A lenda criada por Alencar (1865), em Iracema, constitui, poeticamente, as origens de sua terra natal. A formosa índia tornou-se símbolo do Ceará, e o autor 
traça a relação amorosa entre a jovem da selvagem tribo e o fidalgo português, Martim. O romance e os conflitos do casal predominam em toda a obra.

Em Avatar, temos em Neytiri a figura de uma guerreira, filha do chefe da Tribo, assim como no romance brasileiro. O rapaz, Jake, assemelha-se a Martim, ambos configuram o imigrante apaixonado pela nativa. Elementos como o "Segredo da Jurema", ressurgem com outra denominação, sendo então, o "Segredo de Eywa", na versão fílmica. O lugar, também sagrado, do primeiro ato de amor entre os personagens encontrava-se na natureza, em plena pureza e primitivismo, à sombra de uma árvore. Se o leitor tiver o conhecimento do texto usado como fonte, ficará bem clara a intertextualidade desses aspectos das obras.

Podemos elencar novamente, teoricamente, através de Kock e Cavalcante (2008, p. 30-31), a ocorrência da intertextualidade implícita, principalmente quando se introduz, no próprio texto, o intertexto alheio, sem qualquer menção da fonte, tal qual expressam em suas páginas: "Nos casos de intertextualidade implícita, o produtor do texto espera que o leitor/ouvinte seja capaz de reconhecer a presença do intertexto, pela ativação do texto-fonte em sua memória discursiva”. Em outro momento de pesquisas, encontramos nas palavras de Pellegrini $(1999 ; 2003)$ dados indicativos de que a narrativa verbal e a narrativa visual podem representar possíveis aproximações, como veremos a seguir: "Se a matéria dos fatos, a ação, é vista como movimento, todas as
formas narrativas - sejam as propriamente literárias, como o
romance ou os contos, a lenda ou o mito, seja as formas visuais,
como o cinema e a televisão - estão direta ou indiretamente
articuladas em sequências temporais, não importa se lineares, se
truncadas invertidas ou interpoladas. A diferença entre literatura e
cinema nesse caso, é que, na primeira, as sequências se fazem com
palavras e, no segundo, com imagens."(PELLEGRINI, 1999, p. 17-
18)

Ao ter contato com o texto verbal e o visual, assim como com o conhecimento da temática trabalhada em ambos, do tom de crítica, da exploração e da aculturação, sempre comandados pela ganância do povo capitalista, entendemos que há um entrelaçamento que pode ser visto em ícones e na simbologia implícita no decorrer de leituras verbais e fílmicas, ou seja, as narrativas de cenas coincidentes, o tema, os ideais, as cores, as realidades socioculturais em muito coincidem e dialogam entre si, como constataremos nos próximos itens apresentados.

Revista Leitura V.2 no 54 - Júlio/Dez 2014 - Número temático: Leituras interartes. Do liuro ao cinema: Iracema e Avatar - Maria Aparecida Barbosa Vianna e Katy Evelin Almeida Santos. p. 68- 80 


\section{A temática indianista}

Segundo o teórico Afrânio Coutinho (1975), o autor José de Alencar tornouse um importante representante da fase indianista do romantismo brasileiro. Esse momento literário apresentou a predominância da descrição da natureza, da idealização do selvagem como símbolo do espírito e da civilização nacional em luta contra a herança portuguesa. O indianismo dos autores românticos, para Cândido (1971, p. 21) trazia a tendência de "particularizar os grandes temas", mostrando o indígena com as características desejadas de ética e cortesia.

Portanto, Alencar (1998), em seu livro Iracema, narrou e deu vida ao corpo desse escrito, com a gama poética do livro revelando a relação amorosa, os atos simplificados, representados na obra literária e percebidos no espaço lírico. Através desses escritos, consideramos haver um intertexto com a obra cinematográfica da atualidade, por isso, a seguir, apresentaremos os elementos principais de criação da trama literária e da fílmica, contextualizados em um breve resumo dos aspectos principais do romance Iracema, de Alencar, e do filme Avatar, dirigido por James Cameron, para melhor compreensão e posterior dos aspectos intertextuais presentes, como base às analises deste trabalho, conforme os tópicos a seguir.

\section{Síntese da obra alencariana}

$\mathrm{Na}$ lenda criada em1865, Iracema, o autor explicou na poesia as origens de sua terra natal. A nativa guerreira da tribo dos tabajaras, filha do pajé Araquém, guardava o "Segredo de Jurema", uma das deusas da tribo, ao fabricar para o pajé a bebida sagrada que provocava o "efeito maravilhoso", e tinha sua virgindade consagrada a tal divindade.

Apesar da pureza e da inocência, a moça caiu nos encantos do estrangeiro, após vê-lo durante uma caçada, quando esse se perdeu de seu amigo, Poti, e acabou nas terras inimigas, dos Tabajaras. Exatamente nesse momento ocorreu o encontro entre os dois, e posteriormente a índia entregou-se ao europeu, traindo todas as concepções de sua tribo, sendo esse o primeiro momento conturbador na vida amorosa de ambos.

Revista Leitura V.2 no 54 - Júlio/Dez 2014 - Número temático: Leituras interartes. Do livro ao cinema: Iracema e Avatar - Maria Aparecida Barbosa Vianna e Katy Evelin Almeida Santos. p. 68- 80 
Com o tempo, o relacionamento estreitou-se, ela engravidou, mas o jovem sentia saudades de sua pátria. Os guerreiros, Poti, Martim, os tabajaras e os franceses se tornaram aliados, partiram para a guerra, e ela ficou no litoral. Os homens retornaram vitoriosos, no entanto a jovem profetizou sua própria morte, vinda com o nascimento de seu filho, Moacir. O europeu voltou para casa, apreensivo, imaginando como estaria Iracema e seu filho. Lá estava ela, na porta da cabana, esperando pela morte. Só teve forças para erguer o bebê e apresentá-lo ao pai. Em seguida, morreu.

Ele retornou para sua terra natal, Portugal, levando o filho. Não conseguiu permanecer lá, então voltou ao Ceará, local em que Martim implantou a fé cristã.

Temos neste pequeno resumo as concepções românticas do amor à terra, do nativismo, dos conflitos entre o selvagem e o estrangeiro, do cristianismo, dos amores exacerbados etc.

\section{A obra fílmica de Cameron}

Vivenciamos diariamente enfoques sobre a preservação da natureza, a destruição da mesma pelos homens, nas campanhas ilustrativas dos jornais e revistas, ONGs empenhadas em prol das matas e florestas, enquanto os ativistas protestam contra o desmatamento e a Floresta Amazônia vem sendo considerada o "pulmão do mundo". Representá-la, ou buscar em suas origens os argumentos para uma produção hollywoodiana pode ser uma escolha perspicaz. Exatamente esses elementos encontramos no filme dirigido por James Cameron (2009), Avatar, ao nos apresentar uma realidade futurista, em que a corporação humana RDA explora minérios, e ao acabar com seus recursos naturais, descobre em outro planeta, Pandora, uma fonte de riquezas, da qual querem se apoderar e desfrutar. Como dizem nos filmes, "qualquer semelhança é mera coincidência".

No cenário fictício habita uma espécie de humanoides, chamados Na’vi. Vivem em harmonia com a natureza e veneram uma deusa chamada Eywa. Nessa tribo encontramos uma guerreira, Neyriti, filha do dono da tribo (clã) Omaticaya, ela guarda o "Segredo de Eywa".

Em busca de soluções para a escassez mineral, alguns pesquisadores criam um programa com o corpo de um avatar, permitindo o acesso dos humanos à espécie. 
Dessa forma conseguem obter conexões neurais e controlá-lo, na figura de Jake Sully, um ex- fuzileiro, aventureiro, que foi para Pandora à procura de dinheiro na intenção de realizar uma operação, na esperança da cura da paralisia que o acomete. Seu irmão gêmeo Thomas, trabalhava na equipe, era cientista e morreu. Então o chamam para assumir o corpo de seu avatar, pois possui a mesma genética, embora nunca tenha tido conhecimento do programa, nem conheça o corpo de um avatar ou saiba sobre a cultura dos Na'vis. O rapaz aceita a proposta e os pesquisadores o colocam na função de escoltar o grupo. Aos poucos o ensinam a dominar os comandos, com êxito percebe que pode se locomover e voltar a andar e correr, deixando-o deslumbrado com o movimento de suas pernas no corpo alheio.

Em uma de suas buscas pelas amostras, os cientistas levam-no para escoltálos e ele acaba se perdendo na mata, onde Neityri, uma Na'vi fêmea, encontra-o. No início quis deixá-lo, mas quando percebe que as sementes da árvore da vida o cobriram, resolve ajudá-lo e levá-lo à Árvore-Lar, local de moradia do clã dos Omaticaya.

Aos olhos dos comandantes da operação, a ligação construída com o clã pode trazer benfeitorias aos interesses do grupo, portanto os chefes fazem um trato com Jake de lhe conseguir próteses para a locomoção, em troca de convencer os Omaticaya a saírem da Árvore-Lar, localizada em cima da reserva de Unobtainium.

Com o passar do tempo, o jovem se acostuma e passa a preferir o modo de vida da tribo, além de iniciar um relacionamento com a nativa. Começa, então, a proteger o clã da destruição, por isso seu avatar sofre como consequência o desligamento. Jake e Grace, a botânica da equipe e protetora da natureza, são considerados traidores e por isso vão para um cativeiro. Os oportunistas atacaram a Árvore-Lar, matando muitos nativos, inclusive o chefe do clã, o pai de Neytiri.

Ao serem desligados dos avatares, Jake e Grace passam por momentos difíceis, ela morre. A derrota se aproxima, porém a Deusa Eywa intervém, manda ajuda da fauna e de tudo que habita Pandora, tirando a vantagem da RDA. Os militares acabam expulsos, somente os cientistas ficam. O jovem torna-se líder dos Omaticaya, e tem sua alma transferida permanentemente para seu avatar, por meio da Árvore das Almas, podendo assim desfrutar do amor da nativa.

Os elementos dessa narrativa constituem a base do roteiro, embora com focos e parâmetros divergentes do romance original, mas com vários elos no decorrer das

Revista Leitura V.2 no 54 - Júlio/Dez 2014 - Número temático: Leituras interartes. Do livro ao cinema: Iracema e Avatar - Maria Aparecida Barbosa Vianna e Katy Evelin Almeida Santos. p. 68- 80 
cenas e no enfoque das etnias, da crença pagã, das origens primitivas, em um contraste entre o futuro (a civilização) e a origem (a tribo).

\section{A conservação da natureza (como Alencar vê a natureza / O caos da conservação)}

Como já dissemos, em tempos de mudanças climáticas e questionamentos acerca das transformações ocorridas nos últimos séculos, em virtude da exploração da natureza e do desgaste do planeta, falar sobre o início da civilização e das consequências da devastação quer seja, na televisão, no cinema e na mídia em geral, tornou-se frequente. Sendo assim, houve coerência na busca dos argumentos dos autores do século XIX, um período de pós-independência, de recortes históricos da sociedade americana e das heranças de seus colonizadores.

Se apresentarmos esta situação, não podemos nos esquecer dos nativos, da mestiçagem, do surgimento das novas raças, de culturas tão marcantes, desse povo que foi dizimado, aculturado e teve suas terras tomadas pelo inimigo, o usurpador.

A natureza, um dos principais aspectos do Romantismo, foi tratada por Alencar de maneira a exaltar as belezas naturais do país, o mistério e a grandiosidade do clima tropical, "instaurando o prazer estético da paisagem, descobrindo-a definitivamente para a literatura, ao mesmo tempo fazendo conhecer o Brasil pelas suas descrições" (COUTINHO, 1975, p. 172).

No filme Avatar há, também, a retomada desse aspecto típico do Romantismo, em um misto de aventura, pois praticamente quase todas as tomadas cinematográficas tiveram como cenário a "floresta" de Pandora (uma menção à Floresta Amazônica), o centralizador do conflito entre a conservação do local para a sobrevivência dos nativos, ou a destruição do espaço para a realização da extração dos minérios desejados pelos membros da corporação humana da RDA.

Encaixam-se as temáticas, as atualizações dos interesses pertinentes a cada época, tanto da criação literária, como da fílmica. Quer sejam nos personagens, na caracterização dos ambientes, no mundo futurista em contraste com o passado, a presença dialógica exerce um poder de ligação muito forte, embora não possamos nos esquecer que a compreensão de tais afirmações depende muito do repertório do leitor ou do espectador, pois para que se crie uma rede de sentidos, necessita-se do conhecimento temático, de leituras prévias e de uma percepção aguçada.

Revista Leitura V.2 no 54 - Júlio/Dez 2014 - Número temático: Leituras interartes. Do liuro ao cinema: Iracema e Avatar - Maria Aparecida Barbosa Vianna e Katy Evelin Almeida Santos. p. 68- 80 


\section{A construção e o entrelaçamento temático}

O tema apresentado no discurso fílmico e no literário chamou a atenção e levou a um estudo mais profundo, cuja finalidade encontra-se em uma melhor compreensão dos aspectos do filme Avatar sob o olhar do livro Iracema. A transposição da temática do livro para o cinema implica:

[...] "livro e filme estão distanciados no tempo; escritor e cineasta não têm exatamente a mesma sensibilidade e perspectiva, sendo, portanto, de esperar que a adaptação dialogue não só com o texto de origem, mas com o seu próprio contexto, inclusive atualizando a pauta do livro, mesmo quando o objetivo é a identificação com os valores nele expresso.” (XAVIER, 2003, p. 62.)

Johnson (2003, p. 44) afirma que a intertextualidade entre cinema e literatura apresenta-se, sempre, múltipla e complexa, podendo ser clara ou apenas sugerida a conexão entre os textos ficcionais e os elementos da linguagem visual, salientando ainda, "a fidelidade também geralmente ignora o fato de que a literatura e o cinema constituem dois campos de produção distintos, embora em algum nível relacionados". Para o autor,

\footnotetext{
"enquanto um romancista tem à sua disposição a linguagem verbal, como toda a sua riqueza metafórica e figurativa, um cineasta lida com pelo menos cinco materiais de expressão diferentes: imagens visuais, a linguagem verbal oral (diálogo, narração e letras de musica), sons não verbais (ruídos e efeitos sonoros), musica e a própria língua escrita (creditos, títulos e outras escritas). Todos esses materiais podem ser manipulados de diversas maneiras. A diferença entre a linguagem escrita e a imagem visual, como se costuma dizer: se o cinema tem dificuldade em fazer determinadas coisas que a literatura faz, a literatura também não consegue fazer o que um filme faz.). (JOHNSON, 2003, p. 42)
}

O livro e o filme se contrapõem por tempos longínquos, a obra de um romancista de uma escola literária distinta, acabou se transformando pelas mãos de um roteirista cinematográfico, apresentando intertextos relacionados, possuindo características em comum, com traços fortes em suas obras, como veremos na análise das cenas e das cores a seguir. 
As cenas do filme Avatar configuram-se repletas de cores significativas. Assim como no livro Iracema, a natureza faz-se presente. Percebemos nesse aspecto a presença da brasilidade na predominância do amarelo, azul e verde, além da claridade dando um retoque branco marcante às cenas, como se os raios de sol trouxessem luz espiritual, dinâmica.

Logo nas primeiras cenas tem-se a representação da heroína Iracema, perceptível na figura de Neytiri, ambas protagonistas das representações fílmicas e literárias. Elas tornam-se responsáveis por apresentar uma nova forma de viver a seus amados, Martin e Jake. Portanto, percebemos nesse aspecto um entrelaçamento narrativo, com o mesmo foco de construção do enredo.

Em uma das cenas mais tocantes do filme, a tribo se encontra embaixo da grande árvore sagrada - A Árvore das Almas - realizando um ritual, as flores dessa planta espalham energia positiva para todos. Sabiamente, sob ela o herói, Jake e sua escolhida nativa realizam o seu primeiro ato sexual, demonstrando uma relação pura e verdadeira, ao mesmo tempo protegida pelos laços divinos. Assim como a natureza, a Árvore-mãe representa a essência para a vida dos nativos. Também, sob ela, os nativos tentam transferir a alma de Jake do corpo humano ao seu avatar.

Quando estudamos as cores, sabemos que o branco simboliza pureza, perfeição e representa o absoluto. Por isso, essa cor se relaciona com o sagrado. Em uma batalha, a bandeira branca significa paz.

Há, também, outro tom muito presente na produção cinematográfica, o azul, simbolizando calma, reflexão e intelecto, como a cor do céu e da água; também o infinito e o vácuo de onde toda vida derivou. Os avatares $\mathrm{Na}$ 'vis possuem a tonalidade de suas peles azuis, demonstrando a passividade da tribo. Percebemos, mais uma vez, nesse contexto, uma semelhança com uma das cores da bandeira brasileira, pois o azul simboliza nosso céu. Além disso, surge constantemente a presença das cores verde e amarelo, como em nossa bandeira, representando as matas e o ouro (ou a luz do sol).

No entanto, simbolicamente, o amarelo retrata a cor da traição, e essa tonalidade encontra-se presente em uma das cenas do filme, exatamente quando há o ataque aos nativos, prenunciando o término da confiança, demonstrando ter acabado o bom relacionamento e a sujeição de muitos à morte.

Revista Leitura V.2 no 54 - Júlio/Dez 2014 - Número temático: Leituras interartes. Do liuro ao cinema: Iracema e Avatar - Maria Aparecida Barbosa Vianna e Katy Evelin Almeida Santos. p. 68- 80 
Vemos o verde das matas e da esperança presente no planeta dos avatares, pois moram na Árvore-Lar, vivem cercados pela floresta. Sendo assim, acabar com o verde significa terminar com a vida. Isso apresenta uma referência clara ao processo de desmatamento, que vem ocorrendo em muitas florestas ao redor do mundo, principalmente na Amazônia, foco de pesquisas do diretor cinematográfico, James Cameron, durante o processo de produção das filmagens, cenários e enredo. Sabemos ser a floresta de importância fundamental para os $\mathrm{Na}$ 'vis, pois configura o habitat natural, local de vivência e alimentação, portanto, sua preservação consiste no sinônimo da preservação de suas próprias vidas. A presença do verde torna-se marcante nessas cenas.

O processo simbólico das cores novamente surge nas naves terrestres, cuja intenção centra-se em tentar destruir a Árvore-mãe, nessa cena o veículo de ataque possui a cor preta, simbolizando a morte, o extermínio, a destruição, prevendo algo terrível a acontecer. No caso, a guerra imparcial (por causa da supremacia militar humana frente às flechas primitivas dos avatares).

Mais uma vez encontraremos a tendência cromática, agora no pássaro-rei, Toruk Maktub, ao aceitar apenas a Jake como seu domador, a função do animal consiste em guiar os $\mathrm{Na}$ 'vi no combate final contra os humanos. $\mathrm{O}$ animal possui as três cores que podem simbolizam a guerra: amarelo (traição), vermelho (sangue) e preto (morte).

Após um estudo profundo sobre as cores na história da arte, assim como da simbologia inserida nos meios culturais, destacamos as cenas e a presença constante e aprimorada da coloração na representação gráfica dos elementos de simbologia, dos ícones utilizados para reforçar as ideias e aprimorar as cenas cinematográficas da reprodução fílmica. Todo esse trabalho aprimora o grau de entendimento e interrelaciona o leitor às obras e aos contextos culturais às quais estão inseridas.

\section{Conclusão}

A literatura nos traz personagens e histórias envolventes, porém quando representados na tela do cinema tomam outra dimensão, há uma amplitude da imagem, as tomadas criam discursos, o foco, o olhar do diretor, as imagens ganham novos significados. Os elementos virtuais, configuram-se em imagens, personagens e

Revista Leitura V.2 no 54 - Júlio/Dez 2014 - Número temático: Leituras interartes. Do liuro ao cinema: Iracema e Avatar - Maria Aparecida Barbosa Vianna e Katy Evelin Almeida Santos. p. 68- 80 
cenas, ganham vida, agilidade e traduzem para o público o modo de ver de toda uma superprodução que envolve o elenco, produtores, recursos tecnológicos e humanos, além do roteirista e do diretor (ferramenta fundamental).

Verificamos, no decorrer da análise deste artigo, a intertextualidade temática presente entre duas obras distantes entre si, tanto temporal, como na linguagem, ou seja, Iracema, de 1865, uma produção literária e Avatar, de 2009, uma superprodução cinematográfica. Constatamos também a presença de um processo simbólico com as cores, os temas, imagens e tomadas cujas características marcantes dão ênfase ao processo de construção fílmica e podem ser realçados na pósprodução, já que configuram uma teia de significados implícitos, na esperança da lógica do leitor ou do espectador poder desvendar.

Nas duas obras, constamos a presença marcante da natureza, bem como da tendência do homem em destruir o que ainda não está dentro de si. Martim, em Iracema, só começou a se envolver com os problemas dos índios brasileiros ao se apaixonar pela jovem nativa. Da mesma forma Jake Sully, decide defender os Na'vis da destruição quando se apaixona por Neytiri. Esses aspectos demostram como o amor entre os personagens centrais modifica a intenção de colonização e destruição do homem branco, tal qual uma arma poderosa, sujeita à rejeição e a causar dor nos mais próximos.

Apesar de distantes no tempo e na linguagem, as duas obras se entrelaçam e apresentam diversos pontos intertextuais. Constatamos o intertexto, os pontos de semelhança em que houve o diálogo, percebendo os elementos se repetirem, mesmo que em formas diferentes, mas encontram-se presentes em ambas as produções, ligadas por pontos-chave, propícios à análise e à leitura dos parâmetros verbais e visuais presenciados.

\section{Referências}

ALENCAR, J. de. Iracema. Série Bom Livro. Editora Ática, São Paulo, 1998. BAKHTIN, M. Marxismo e Filosofia da Linguagem. 6. ed. São Paulo: Hucitec, 1992.

Estética da Criação Verbal. 2. ed. São Paulo: Martins Fontes, 1997.

CAMERON, J. Avatar. Studio Cinematográfico da 20th Century Fox, 2009. Disponível em: http://pt.wikipedia.org/wiki/Avatar_(filme). Acesso em 20/04/2013.

CÂNDIDO, A. Formação da literatura brasileira. São Paulo: Martins Editora, 1971. COUTINHO, A. Introdução à literatura no Brasil. Rio de Janeiro: Editora Distribuidora de Livros Escolares, 1975.

Revista Leitura V.2 no 54 - Júlio/Dez 2014 - Número temático: Leituras interartes. Do liuro ao cinema: Iracema e Avatar - Maria Aparecida Barbosa Vianna e Katy Evelin Almeida Santos. p. 68- 80 
KOCH, I. G. V.; ELIAS, V. M. Ler e compreender os sentidos do texto. São Paulo: Contexto, 2010.

KOCH, I. G. V., BENITES, A., C. e CAVALCANTE, M. Intertextualidades Diálogos Possíveis. 2a ed. São Paulo: Cortez, 2008.

PELLEGRINI, T. A imagem e a letra: aspectos da ficção brasileira contemporânea. Campinas/ S. P., Mercado de Letras/FAPESP, 1999.

PELLEGRINI, T. et al. Literatura, cinema e televisão. São Paulo: Ed. Senac, 2003.

XAVIER, I. in PELLEGRINI, T. et al. Literatura, cinema e televisão. São Paulo: Senac, 2003.

WALTY, I. L. C.; FONSECA, M. N. S.; CURY, M. Z. F. Palavra e imagem: leituras cruzadas. Belo Horizonte: Editora Autêntica, 2000. 